\title{
Necrológica del Outsider Reinhart Koselleck: el «historiador pensante» y las polémicas de los historiadores *
}

\author{
FAustino Oncina Coves \\ Universitat de València/Instituto de Filosofía del CSIC
}

A la Oma

RESUMEN. Reinhart Koselleck es un autor de difícil encasillamiento, pues su historia conceptual es repudiada a la par que rentabilizada tanto por la Filosofía como por la Historia. En este trabajo se analiza su actitud, ora discreta, ora vehemente, frente a las disputas de los historiadores y de los filósofos de su país, y muy en particular frente a la polémica en torno a la implicación de ambos gremios en el nacionalsocialismo, que a su vez ha suscitado un debate, aún inconcluso, acerca de los afectos y desafectos entre la ciencia que estudia el pasado y la memoria, y ha desatado la querella de los memoriales a propósito del monumento a las víctimas del Holocausto. Koselleck rastrea los principales hitos modernos en la tentativa de una iconografía de la muerte violenta, de una estética de la memoria. La semántica histórica alberga todos los ingredientes requeridos para animar un uso público de la razón histórica y se troca en medio de autoesclarecimiento histórico del presente.

Palabras clave: Historia Conceptual, polémica de los historiadores, nazismo, memoria, memoriales.
ABSTRACT. Reinhart Koselleck is an author difficult to classify, since his conceptual history is rejected, and at the same time taken advantage of, by both philosophy and historiography. This paper analyses Koselleck's attitude, sometimes tactful, at other times passionate, towards the polemics of the historians and philosophers of his country, and particularly towards the controversy concerning the involvement of both groups in Nazism-a controversy that has provoked a debate, still open, about the affections and disaffections between the science which studies the past, and memory, and has also unleashed a dispute about memorials motivated by the monument to the victims of the Holocaust. Koselleck tracks down the main modern milestones of the attempt to develop an iconography of violent death and an aesthetics of memory. Historical semantics possesses all the ingredients required to enliven the public use of historical reason, and it becomes a means for a selfclarification of the present.

Key words: Conceptual History, polemics of the historians, nazism, memory, memorials.

* Este trabajo forma parte del proyecto de investigación HUM2007-61018 del Ministerio de Educación y Ciencia. 


\section{Un intruso para dos gremios}

Sorprende que un autor de la talla intelectual de Koselleck haya sido descrito con frecuencia como marginal o incluso como un marginado. Cuando recibió el premio del Historischer Kolleg, el encargado de la laudatio, R. Vierhaus, lo caracterizaba como un «intruso» (Aussenseiter). Tras su fallecimiento, su caro colega H. Meier recordaba que Gadamer lo llamaba «el historiador pensante» (denkenden Historiker), y que justamente por hallarse en ese intersticio, o mejor dicho interregno, era repudiado por historiadores y filósofos. M. Jeismann, un colaborador suyo en los postreros años, refiere en el sentido momento del adiós que su «temperamento filosófico» era la causa del desdén que le dispensaba el gremio. Son conocidos los chascarrillos que le dedicaba su soberbio compañero en Bielefeld, H. U. Wehler, quien, amén de tildarlo de «filósofo histórico» (historischer Philosoph), se apresuró a escribir, casi apenas alumbrada, el epitafio de la historia conceptual. La animosidad de la denominada «historia social crítica» le incitó a apearse de la revista Geschichte und Gesellschaft, de la que fue cofundador. Como fallaron los malos presagios que auguraban una vida efímera a la Begriffsgeschichte, el pope Wehler se cruzó de nuevo en su camino cuando Koselleck afrontó la investigación sobre la iconología política del culto a la muerte violenta, boicoteando la publicación de sus resultados en una afamada colección editorial. A pesar de un difuso asunto que lo separó de los historiadores conceptuales, Gadamer demostró más amplitud de miras, confesando que en Heidelberg él aprendió más de su alumno que éste de su maestro ${ }^{1}$. El discípulo dio muestras de esa madurez de juicio al leer el discurso conmemorativo del octogésimo quinto cumpleaños de quien llegaría a rebasar el siglo, al rehuir el tópico y condescendiente panegírico y buscar en su lugar el diálogo y hasta la confrontación, resistiendo su Histórica el poder de subsunción universal de la hermenéutica filosófica. Koselleck siguió aquí la recomendación de su estimado Lessing, según la cual la disputa es el mejor purgante de dogmatismos y gigantomaquias: «Pero, dicen, ¡la verdad gana así tan pocas veces! ¿Tan pocas veces?

1 R. Vierhaus, «Laudatio auf den Preisträger», en Dritte Verleihung des Preises des Historischen Kollegs, München, 1991, p. 27; Ch. Meier, «In den Schichten der Zeit. Geschichte als Leib gewordene Erfahrung: Zum Tode des Bielefelder Historikers Reinhart Koselleck», en Die Zeit, 09.02.2006; M. Jeismann, «Das Jahrhundert unter der Haut. Die Besiegten schreiben die Geschichte: Zum Tode des deutschen Historikers Reinhart Koselleck», en FAZ, 06.02.2006; «Begriffsgeschichte, Sozialgeschichte, begriffene Geschichte. Reinhart Koselleck im Gespräch mit Christof Dipper», en Neue politische Literatur, 43 (1998), pp. 197-199; Ch. Dipper, «Die "Geschichtlichen Grundbegriffe". Von der Begriffsgeschichte zur Theorie der historischen Zeiten», en Historische Zeitschrift, 270 (2000), pp. 282-283; Hans-Ulrich Wehler. Eine lebhafte Kampfsituation. Ein Gespräch mit Manfred Hettling und Cornelius Torp, München, Beck, 2006, p. 91; J. Grondin, Hans-Georg Gadamer. Una biografia, Barcelona, Herder, 2000, p. 398; Die Lektion des Jahrhunderts. Ein philosophischer Dialog mit Riccardo Dottori, Münster, Lit Verlag, 2002, pp. 90-91. 
Aunque no se hubiese establecido la verdad nunca mediante polémicas, jamás hubo polémica en que no saliera ganando la verdad. La polémica alimentó el espíritu de prueba, mantuvo en incesante excitación a los prejuicios y a los prestigios; en una palabra, impidió que la falsedad acicalada se aposentara en el lugar de la verdad» ${ }^{2}$. Aunque se enzarzó en una fructífera querella con Gadamer, acaso porque el diálogo era la patente de la hermenéutica y quiso cumplimentar al homenajeado en su hogar filosófico, Koselleck se abstuvo de participar en la renombrada "polémica de los historiadores» (Historikerstreit), que, sin embargo, ha acabado salpicándole póstumamente, tal vez por no ver en ella sino un ajuste de cuentas en el que entraba en liza el mero afán de desquite. Lessing, sin embargo, haciendo historia virtual, sí que se habría entrometido.

El historiador podría haber apelado a otra virtud lessinguiana para justificar su actitud reservada. En sus Diálogos para francmasones de 1778 Lessing pone en boca del ilustrado una admonición: «Se puede llegar a abusar de una verdad de la que cada cual juzga según su propia situación [...]. El sabio no puede decir lo que es mejor callarse» ${ }^{3}$. Claro que esa técnica de la reticencia la fraguó un hombre en tiempos de oscuridad ${ }^{4}$, distintos de los nuestros. La discreción o absentismo polemista la explica Koselleck con motivo del libro El incendio de Jörg Friedrich ${ }^{5}$, una obra sensacionalista que equipara los bombardeos en Alemania al Holocausto. En lo concerniente a los ataques aéreos aliados o a la aniquilación de los judíos, ha sido reservado para no herir a los demás, pero el silencio no significa en absoluto eliminación de la culpa. Se trata de un silencio como mínimo de decoro, tras el cual había que ocultar las propias reflexiones para comunicarlas en situaciones amistosas. Los alemanes tienen un derecho a su propio recuerdo, que es casi un derecho humano. Sin embargo, Koselleck ha sido alineado en alguna ocasión con Andreas Hillgruber, en la diana, junto a Ernst Nolte, de los embates de Habermas contra el revisionismo histórico. Califica ese torneo de penosa puesta en escena de vanidades autoalimentadas, y defiende a los difamados Hillgruber y Nolte ${ }^{6}$.

2 G. E. Lessing, La ilustración y la muerte: dos tratados, edición a cargo de A. Andreu, Madrid, Debate, 1992, pp. 2-3.

3 G. E. Lessing, Escritos filosóficos y teológicos, edición a cargo de Agustín Andreu, Madrid, Editora Nacional, 1982, p. 612.

4 Véase Hannah Arendt, Hombres en tiempos de oscuridad, Barcelona, Gedisa, 1990.

5 El Incendio: Alemania en la guerra de los bombardeos, 1940-1945, Madrid, Taurus, 2003.

6 A Hillgruber por haber sido manipulado y a Nolte porque, a pesar de la desafortunada formulación de su hipótesis, plantea una cuestión aún por contestar: ¿Cuál fue la influencia de la Revolución bolchevique sobre la mentalidad de los alemanes? («Reinhart Koselleck im Gespräch mit Renate Solbach. Öffentlichkeit ist kein Subjekt», en Iablis, 2003, pp. 14-16). Véase el excelente trabajo de Chris Lorenz, «Encrucijadas. Reflexiones acerca del papel de los historiadores alemanes en los debates públicos recientes sobre historia nazi», en M. Cruz y D. Brauer (eds.), La comprensión del pasado. Escritos sobre la filosofía de la historia, Barcelona, Herder, 2005, pp. 335-381. 
En su libro A paso de cangrejo, Günter Grass recurre a una metáfora escatológica para ejemplificar la relación de los alemanes con su pasado: «La historia, mejor dicho, la historia removida por nosotros es como un retrete atascado. No hacemos más que tirar de la cadena, pero la mierda sube siempre» ${ }^{7}$. A pesar de todas las estrategias y estratagemas (represión, disociación, proyección, sublimación) empleadas para camuflar esa memoria, ésta acaba siempre, tarde o temprano, aflorando. Eso le ha ocurrido a este mismo pontificador de la entera verdad histórica, que ha dosificado la suya propia, exponiéndola a plazos, y dejando para la última entrega, Pelando la cebolla, como una operación de marketing impecable, la parte más sabrosa. Es cierto que, a diferencia de otros, no ha sido cogido in fraganti, pero, no obstante, este arquetipo moral ha bajado del pedestal y ahora el eco de sus proclamas a favor de conocer «toda la historia» de su país suena a arenga moralista. Sin duda las apelaciones morales viven de la fuerza del argumento, no de la intachabilidad del autor. Los discursos en los que Grass recordaba a los alemanes su culpa y su responsabilidad, o continúan siendo en sí verdaderos o no lo fueron nunca. Quien afirma ahora que Grass ha perdido su credibilidad, debería preguntarse si cree en la dignidad de la moral o sólo en la personalidad prominente del moralista. Hegel nos dio hace más de dos siglos una lección magistral a este respecto en La positividad de la religión cristiana (1795-96). El propio Grass habría contribuido a la llegada de la hora de los hipócritas, puesto que no es la opinión pública, de la que ahora se queja, la que habría dramatizado su pecado de juventud, sino que él mismo habría convertido su confesión y autodenuncia en un instrumento de promoción de ventas. Ahí se aprecia una coquetería asombrosa ${ }^{8}$.

\section{Disputas de los historiadores y de los filósofos}

Estas disputas resucitan en Alemania como el ave fénix y nunca pueden darse por definitivamente zanjadas. La última es el penúltimo capítulo de la inextinguible «polémica de los historiadores», que ha tenido como protagonistas directos a Joachim Fest y a Jürgen Habermas e indirectos a Hans-Ulrich Wehler y a Reinhart Koselleck. Dos de ellos ya han fallecido. Si Wehler y Kocka, al socaire de su historia social crítica (con reminiscencias habermasianas), desempeñaron el papel de fiscales de velados tradicionalismos y pujantes neoconservadurismos, ahora les tocaba sentarse en el banquillo de los acusados. La jugada es perfecta. Ya nadie puede tirar la primera piedra, pues ya na-

7 Günter Grass, A paso de cangrejo, Madrid, Punto de lectura, 2004, p. 134. Cfr. Juan Cruz, «Günter Grass sirvió en las SS», en El País, 12.08.2006, p. 27.

$8 \mathrm{Cf}$. Jens Jessen, «Und Grass wundert sich. Die öffentliche Selbstrechtfertigung ist so unnötig wie ärgerlich», en Die Zeit, 17.08.2006, p. 1. 
die está libre de sospecha. La trama es como sigue. En su autobiografía Yo no (Ich nicht), donde narra la ejemplar resistencia de su familia al nacionalsocialismo, J. Fest cuenta una anécdota envenenada sobre una de las «cabezas dirigentes del país» con un puesto de responsabilidad en las Juventudes Hitlerianas en las postrimerías del Imperio. Varias décadas después, en el curso de una fiesta de cumpleaños, un subordinado de entonces le pasó una nota redactada por este superior en la primavera de 1945, que contenía una «apasionada declaración de adhesión al Führer y la inquebrantable esperanza en la victoria final». El aludido, según diversos testigos, apretujó el papel, se lo introdujo en la boca y se lo tragó: «Se puede ver en eso una especie de liquidación del siniestro, para desembarazarse de una vez por todas del lastre del pasado». Wehler, amigo de Habermas desde la adolescencia y una fuente de primera mano para lo aquí relatado, ha negado la veracidad de esas palabras y ha dado su versión, de la que ahora prescindimos. Lo único relevante para nuestro propósito reside en que la fiesta mencionada habría sido la del cumpleaños de Koselleck, el sujeto del mal trago Habermas (fácil de identificar por haber titulado su respuesta a Nolte «Una especie de liquidación del siniestro») y el subalterno Wehler. De acuerdo con lo que Fest le comunicó a Wehler en abril de 2006, Koselleck mismo, usado con una función legitimatoria, le habría «confirmado plenamente» esta historia e incluso añadido «detalles todavía desconocidos hasta entonces». Wehler desmiente su autenticidad. Mientras tanto Koselleck ha fenecido y obviamente ya nadie puede recabar de él ulterior información. Wehler destaca que Fest hizo caso omiso de su respuesta y prefirió ceder a la tentación de la denuncia de un adversario político. Evoca la crítica de Habermas al apoyo que Fest le brindó a Nolte en la Historikerstreit y saca a colación el escándalo en torno a Günter Grass, preguntándose retóricamente si la revista Cicero, que en el número de noviembre recogía ese rumor a través de la pluma insidiosa de un antiguo delfín de Fest en el Frankfurter Allgemeine Zeitung, Jürgen Busche, se propone aprovecharse de la coyuntura para airear lados oscuros inventados de la crónica del nacionalsocialismo ${ }^{9}$.

9 Hans-Ulrich Wehler, «Habermas hat nichts verschluckt. Warum der Philosoph keinen Grund hatte, seine Zeit bei der Hitlerjugend zu vertuschen - zur Genese eines perfiden Gerüchtes», en Die Zeit, 2.11.2006, p. 44. Cf. R. Leicht, «Fest, Habermas, Historikerstreit», en Íd., p. 44. El hijo de Fest y editor de la autobiografía (que en castellano reza Yo no. El rechazo del nazismo como actitud moral, Madrid, Taurus, 2007 — de esta versión y de las reediciones en alemán ha sido podada, por decisión judicial, la malévola insinuación-) sale en defensa de su padre justificando, por el empeoramiento del estado de salud de su progenitor, que le impidió retomar el manuscrito, la omisión de la verdadera historia de este asunto que Wehler le transmitió por carta en abril (Alexander Fest, «Der Brief wurde nicht verschluckt. Joachim Fest konnte die irrige Habermas-Anekdote in seinen Memoiren nicht mehr korrigieren. Er war schon todkrank, als Hans-Ulrich Wehlers Richtigstellung eintraf», en Die Zeit, 9.11.2006, p. 62). Además de Koselleck, Hermann Lübbe también es citado como posible propagador de semejante rumor. Gereon Wolters recuerda que el libro de aquél Politischer Moralismus. Der Triumph der Gesinnung über die Urteilskraft recrea la irrisoria escena supuestamente protago- 
Así pues, Fest habría aguardado esta oportunidad para saldar una deuda pendiente. Como director de las páginas culturales del citado diario, le había servido a Ernst Nolte como plataforma de su revisionismo. Nolte había afirmado, por un lado, que el crimen organizado por los nazis del exterminio de los judíos, «con la única excepción del proceso de gaseamiento», no fue en absoluto singular (einmalig)»; por otro, Hitler había planeado su «acto asiático» del genocidio sólo como reacción al genocidio estalinista. La diferencia entre uno y otro era de sofisticación técnica. Puesto que «un nexo causal es probable», vale decir: Hitler y Auschwitz como reacción a Stalin y al Archipiélago Gulag. Si el artículo de Nolte era del 6 de junio de 1986 y la réplica de Habermas del 11 de julio, Fest cohonestaba la tesis de Nolte con una andanada de invectivas contra el francfortiano el 29 de agosto ${ }^{10}$. Desde entonces Fest tuvo que soportar esa mancha en su reputación y al final sintió la necesidad de compartir con Habermas un poco de esa porquería a la que se refería Grass. El morbo ha salpicado póstumamente a Koselleck, quien, junto, p. ej., a Hermann Lübbe, aparece como la «garganta profunda», el presunto propagador de este chisme. Así lo sugiere una conferencia de Gereon Wolters ${ }^{11}$, que sólo da crédito a Wehler y a Habermas, y donde emerge el último como un héroe impoluto. La hija de Koselleck, Katharina ${ }^{12}$, me ha corroborado que su padre conocía la historia y la contaba de vez en cuando, pero, si le hacían consultas «oficiales», siempre remitía discretamente a los afectados. No descarta que hayan involucrado a su progenitor so pretexto de lo que llama «el habitual numerito de Carl Schmitt» (die übliche Carl Schmitt-Nummer). Así lo insinúa el propio periodista de Cicero, apoyado, supongo, no sólo en el reconocimiento explícito e implícito que Koselleck le manifiesta a tan luciferino personaje, sino en que las alusiones de Habermas ${ }^{13}$ al profesor de Biele-

nizada por el dechado de político moralista, y la esperpéntica descripción concluye así: «Esto es lo que puede llamarse en sentido literal "represión" (Verdrängung), y más concretamente por ingestión [incorporación] (Einverleibung), y en sentido figurado negación a imputar a la propia identidad de origen lastres del propio pasado» (Berlín, Corso bei Siedler, 1987, pp. 72 s.). Lübbe, por el contrario, calla sobre el hecho de que en 1944, con menos de 18 años, se convirtió en miembro de pleno derecho del partido nazi (Gereon Wolters, Vertuschung, Anklage, Rechtfertigung. Impromptus zum Rückblick der deutschen Philosophie aufs "Dritte Reich», Bonn, Bonn University Press, 2004, pp. 31-32).

10 «Die geschuldete Erinnerung. Zur Kontroverse über die Unvergleichbarkeit der nationalsozialistischen Massenverbrechen», en FAZ, 29.08.1986. Véase Historikerstreit. Die Dokumentation der Kontroverse um die Einzigartigkeit der nationalsozialistischen Judenvernichtung, München, Piper, 1987.

11 Correo electrónico fechado el 8 de noviembre de 2006.

12 Correo electrónico fechado el 11 de noviembre de 2006.

13 «Crítica de la filosofía de la historia (1960)», en Perfiles filosófico-políticos, Madrid, Taurus, 1965, pp. 389-390; «Carl Schmitt en la historia de la cultura política de la República Federal. La necesidad de continuidades alemanas», en Más allá del Estado nacional, Madrid, Trotta, 1997, p. 30. Koselleck se ha referido a la fama de schmittiano que le acompañó desde la disertación y al hándicap que ello significó para su carrera académica. En la entrevista concedida a una revista, afirma que la tesis doctoral «le resultó [a su mismo padre] demasiado 
feld siempre han estado mediatizadas por la denuncia de que las tesis de éste no hacían sino continuar la estela siniestra del jurista comprometido con el Tercer Reich. Pero el articulista no se recata en resaltar que los dos principales actores, Habermas y Wehler, a quienes disculpa maliciosamente que en su época de escolares se enrolaran en un grupo nacionalsocialista, estuvieran bajo la égida el primero de Erich Rothacker, militante del partido pardo, y de Oskar Becker, el único discípulo de Heidegger que fue nazi, y el segundo de Theodor Schieder, que tuvo que maquillar su currículum para no sonrojar a la universidad de la posguerra. Podemos seguir atando cabos. Junto a Schieder, otro canterano del clan de Königsberg al servicio de la causa de la desjudaización fue Werner Conze, que inició a Koselleck en la historia social en Heidelberg y coeditor del macrodiccionario Conceptos Históricos Fundamentales. Luego, aun sin quererlo, Koselleck está en el ojo de este sempiterno huracán.

Koselleck se zafó del círculo de influencia de Gadamer, pero no se salió del todo de esa órbita intelectual, ya que todavía con un pie en Heidelberg comenzó a frecuentar el itinerante grupo de investigación interdisciplinar «Poética y Hermenéutica». Una doble base común al grupo fue el apego al sentido estético y el interés en la semántica histórica. Desde el punto de vista hermenéutico, la experiencia estética y la histórica están hermanadas ${ }^{14}$. En este influyente «colegio invisible» se dieron cita las tres variantes de la historia conceptual hegemónicas entonces en Alemania: la hermenéutica, la compensatoria (representada por dos miembros del Collegium de Münster o Escuela de Ritter, Odo Marquard y Hermann Lübbe) y la entrelazada con la historia social. El interrogante sobre el pasado de los tres padres fundadores, Gadamer, Joachim Ritter y Werner Conze, tenía que plantearse antes o después.

schmittiana, y sentir aversión hacia Carl Schmitt era entonces propio del prurito profesional de casi todos los colegas. Manifestar en el Prólogo mi agradecimiento a Schmitt fue ya un acto de coraje. Pues apenas nadie se había atrevido por entonces a hacer algo así, aunque todos sus escritos fueron leídos y discutidos. Por lo demás, eso me costó mi primera cátedra. En Constanza mi nombre - como también el de Hans Blumenberg - fue tachado de la lista de los aspirantes entre otras razones con el argumento de que era «schmittiano», después de tener ya en el bolsillo la aceptación de mi candidatura por parte de la Facultad» [Mittelweg 36, 2 (2003), p. 75]. En el discurso que pronunció con motivo del quincuagésimo aniversario de su doctorado en Heidelberg abundó en esa misma machacona impresión: «Quien se mostraba agradecido con Carl Schmitt era señalado como portavoz suyo. Quien citaba las teorías de la conspiración del siglo XVIII, se convertía él mismo en un teórico de la conspiración. Quien criticaba un dualismo inspirado política o moralmente, se convertía en un dualista» [Reinhart Koselleck, «Dankrede am 23. November 2004», en Stefan Weinfurter (ed.), Reinhart Koselleck (1923-2006). Reden zum 50. Jahrestag seiner Promotion in Heidelberg, Heidelberg, Universitätsverlag Winter, 2006, p. 55].

14 «Vorwort» a Hans Robert Jauss (ed.), Nachahmung und Illusion, München, Fink, 1964 (2. a edic. 1969), pp. 6-7; H. R. Jauss, «Epilog auf die Forschungsgruppe "Poetik und Hermeneutik"», en G. V. Graevenitz y Odo Marquard (eds.), Kontingenz [Poetik und Hermeneutik, vol. XVII), München, Fink, 1998, pp. 525-533. Además de intervenir en varios de los volúmenes publicados, su huella es rastreable en una terminología que ha pasado a pertenecer al acervo común al grupo: Sattelzeit, Erfahrung und Erwartung... (pp. 527-529, 532-533). 
Era una mera cuestión de tiempo. Habermas ${ }^{15}$ fue un azote para todos ellos, y ahora, como un bumerán, les golpeaba también a la Teoría Crítica y a sus ramificaciones en la historiografía la acusación de continuismo.

\subsection{La amnesia de una pléyade: de Clío a Casandra}

Efectivamente, una de las últimas refriegas sonadas en las que se han visto involucrados conspicuos historiadores de las tres generaciones, la de los perpetradores, la de sus hijos y la de sus nietos, ha girado en torno a la implicación del gremio en el nacionalsocialismo. En la misma se vio envuelto Koselleck oblicuamente - quizá porque muy pronto confesó su fascinación por personajes claramente marcados-, a diferencia de otros eminentes profesores de Bielefeld, que durante un cierto tiempo desempeñaron, o quisieron hacerlo, el papel de tribunal sin mácula no sólo científico sino también moral de sus colegas. No parecieron usar el mismo rasero para los propios ancestros académicos que para los ajenos, y el empleo de una doble vara de medir les está pasando factura. Sin duda es incorrecta la ecuación entre historia y memoria, pero, más allá de su insoslayable distinción, es obvia la mutua impronta de la una en la otra ${ }^{16}$. En Alemania, además y sin remontarse a la tenebrosa «quie-

15 A los compensadores se les antoja pueril la acusación de reaccionarismo: «Parece que en este mundo negativo ya sólo merece afirmación lo contrario de la afirmación: el No absoluto a lo negativo. Las actividades humanas, incluidas las ciencias del espíritu, parecen legitimables sólo mediante su apelación a lo negativo, como integrantes del proyecto de destrucción de la realidad negativa. Por eso, también las ciencias y justamente las ciencias del espíritu son justificadas únicamente por su ruptura con la realidad. Entonces, quien no rompe o no rompe lo suficiente con ella parece malo, puesto que es "culturalmente conservador". Sólo lo contrario de ese conservadurismo parece merecedor de afirmación; las actividades humanas, incluidas las ciencias del espíritu, son humanas sólo cuando no son "culturalmente conservadoras", sino culturalmente revolucionarias, negaciones de un mundo negativo.

Este No absoluto y su represión de lo positivo es la causa de que las compensaciones positivas, que no son ese No absoluto, sean negadas o incluso atacadas como reaccionarias. Pero esas compensaciones positivas existen y alivian los horrores del mundo. Ese ser carencial que es el ser humano compensa sus carencias físicas con la cultura». Marquard señala especialmente a Habermas y a Schnädelbach como los instigadores de ese falso maniqueísmo de conservadores reaccionarios e innovadores: «considero un invento el nexo entre la teoría de la compensación y el conservadurismo cultural: hay muchas compensaciones que son innovadoras» (Odo Marquard, Filosofía de la compensación, Barcelona, Paidós, 2001, pp. 42-43).

16 Debo a Antonio Gómez Ramos el estímulo para repensar los lazos entre historia y memoria en Koselleck, de los que éste se ocupó con mayor frecuencia en el ocaso de su vida. Precisamente en su último trabajo publicado en alemán — hasta donde sé — aborda esta cuestión reconociendo que «escribir y hablar sobre recuerdo e historia se ha convertido en una moda desde hace aproximadamente 2 decenios», y la razón de ello estriba en que cada vez hay menos testigos de las catástrofes y los crímenes del siglo precedente. Y aquí se pregunta explícitamente: «¿Qué hace el recuerdo? Abre el espacio a lo que puede denominarse "historia" (Geschichte). La oposición memoria (Erinnerung) versus historia, evocada hoy gustosamente, era inconcebible (undenkbar) antes de la época de la Ilustración, cuando todavía los testigos oculares o, mejor aún, los actores con sus memorias podían ser llamados los mejores historiógrafos» 
bra de la civilización» pero con un inexorable efecto de anámnesis, la lucha contra la represión del recuerdo se convirtió en una cruzada tras la reunificación al tener que evaluar - evaluación que alcanzó el tono en ocasiones de un juicio sumarísimo - a sus homólogos orientales a fin de dictaminar si eran dignos de seguir formando parte de las filas de la profesión. En ese momento la razón de ser de la disciplina se centraba en denunciar el olvido selectivo y la amnesia colectiva y en erigirla en una ciudadela capaz de salvaguardar institucionalmente la verdad. Esos eminentes profesores hicieron de sus cancerberos, y su hybris constituyó a menudo el ariete contra tanto falsario. La caja de Pandora se abrió irreversiblemente en 1998 (ya antes había habido tentativas todavía tímidas). Historiadores marginales y marginados fueron desmontando la imagen olímpica que se había prefabricado la historia oficial, y el deterioro a partir de entonces fue in crescendo. Hasta entonces y según la nomenclatura aceptada por asentimiento, la mayoría de los historiadores durante el Tercer Reich engrosaron la categoría de nacionalistas normales contemporizadores, frente a una pequeña minoría de colaboracionistas y la todavía más exigua de resistentes. La vanguardia de los historiadores de la posguerra integraba ese henchido grupo intermedio que vivía en una suerte de «exilio interior» (innere Emigration), lo que le permitía gozar de cierta autonomía mental. A esa presunta independencia, una zona gris equidistante de la complicidad y la insurgencia, se la denominó Resistenz — según la fórmula de M. Broszat, a fin de deslindarla de la résistance, en la que destacaron ilus-

(«Der 8. Mai zwischen Erinnerung und Geschichte», en Rudolf von Thadden y Steffen Kaudelka (eds.), Erinnerung und Geschichte. 60 Jahre nach dem 8. Mai 1945, Göttingen, Wallstein Verlag, 2006, p. 13). Algunos de sus temas tardíos (sobre los cuales ya hizo esporádicas incursiones previas) le afectaban personalmente: sueños en el Tercer Reich, figuras y funciones del recuerdo, monumentos a los caídos e iconología política de la muerte violenta, la manera de conmemorar a las víctimas del nacionalsocialismo... Su propia vivencia le sirve de venero y piedra de toque de la teoría, lo que no conlleva que ésta sea destronada por la empiria, pues es notorio el afán de incardinar sus observaciones en categorías antropológicas universales posibilitadoras de comparaciones desde la antigüedad hasta el presente. En 1988 define tres modos fundamentales de la experiencia humana (experiencia primaria única, experiencia hecha repetidamente y por eso comunicable intersubjetivamente, y experiencia fundada mediante reflexión histórica, esto es, ex post) y las relaciona con tres formas fundamentales de la historiografía: Aufschreiben (fijar y explicar acontecimientos únicos), Fortschreiben (producir nexos entre historias almacenadas diversamente) y Umschreiben (revisión del modo de extraer experiencias de las fuentes, de establecer enlaces y de interpretar la historia retrospectivamente). $\mathrm{Si}$ bien en este ensayo la mayoría de los ejemplos proceden de la antigüedad, el epígrafe dedicado al primer modo de experiencia cabría leerlo como una meditación de Koselleck sobre la propia vivencia: «Se trata de un modo de experimentar que es vivido o sufrido de nuevo por cada hombre, consciente o inconscientemente. [...]. Por eso tiene sentido que los enfoques metodológicos de los historiadores remitan a las experiencias completamente personales que han tenido y sin las que no cabe entender sus innovaciones» [ «Cambio de experiencia y cambio de método. Un apunte histórico-antropológico» (1988), en Estratos del tiempo, Barcelona, Paidós, 2001, p. 50]. Conviene no preterir esto al valorar la diferencia que con posterioridad introducirá entre experiencia y recuerdos primarios y secundarios. 
tres historiadores franceses-. Fue principalmente un sesentayochista desclasado académicamente, Götz Aly, quien, haciendo acopio de datos demoledores, desenmascaró a los mandarines de los historiadores germanos (se habían sucedido en la presidencia de su asociación desde 1962 a 1977), K. D. Erdmann, Th. Schieder y W. Conze ${ }^{17}$. Los dos últimos no sólo fueron desalojados de ese nebuloso limbo de la Resistenz, sino que ahora se desvelaba su militancia a guisa de intelectuales orgánicos del pangermanismo. Lo más enojoso no fue el escaso sentido crítico - en comparación con su severidad en el trato con cualquier colega coetáneo mínimamente sospechoso- que evidenciaron estos enfants terribles (hablamos de Hans-Ulrich Wehler y Jürgen Kocka ${ }^{18}$, p. ej.) con sus otrora mentores, ahora rebajados a la condición de sabios ganapanes sin ningún empacho en hacer de su ciencia el escabel de una pérfida ideología, sino que ese lavado del pasado contravenía el código deontológico de la profesión - la custodia de la verdad histórica y el rigor frente al engaño y la propaganda - (luego no hablamos de un pecado de juventud, venial, sino capital, mortal en el caso de un historiador de oficio), y dejaba muy tocada a la «historia social crítica», que se había mostrado muy

17 «Theodor Schieder, Werner Conze oder die Vorstufen der physischen Vernichtung», en W. Schulze y O. - G. Oexle (eds.), Deutsche Historiker im Nationalsozialismus, Frankfurt a. M., 1999, pp. 183-215.

18 La relación de Wehler y Kocka con la Begriffsgeschichte ha girado en torno al historicismo (que para ellos es reprobable) y la teoría de la modernización (en la medida en que ambos han propugnado una superación, controlada historiográficamente, del pasado de la nación alemana). Mientras que para Koselleck hay una paridad y complementariedad entre la dimensión hermenéutica y la socialhistórica, Wehler y Kocka han relegado la hermenéutica. Quizá entendieron maniqueamente el choque Gadamer-Habermas, que, en términos simplistas, llegaron a encarnar, respectivamente, el conservadurismo y el liberalismo, cuando en realidad Habermas aboga por una Tiefenhermeneutik. Otro punto del litigio estriba en que Koselleck no ha aceptado el concepto de Sonderweg por considerarlo débil teóricamente, nulo cognoscitivamente y propio de una historización normativa. Son conocidas las puyas que lanza contra la moralización de la historia y de la política, que abocan a una suerte de optimismo terrorista y a una jibarización, cuando no decapitación, de la responsabilidad. La metacrítica de Gadamer y Koselleck arremete contra la Ilustración, la época de la crítica. También se produjeron divergencias en torno a la línea de investigación especial común «Bürgertum». Wehler no admitió las aportaciones sobre los monumentos de los colaboradores de Koselleck en la serie «Beiträge zur europäischen Gesellschaftsgeschichte» unter dem Obertitel «Bürgertum». Koselleck las alojó finalmente en su colección «Sprache und Geschichte». Éste y su equipo realizan una investigación comparativa, internacional, y aquél nacional («Begriffsgeschichte, Sozialgeschichte, begriffene Geschichte», pp. 197-199, 205). Koselleck participó de soslayo en el debate sobre el Sonderweg, ligado nolens volens al Holocausto, en la medida en que surge en un marco prefigurado por la controversia Fischer, que implícitamente defendió la mímesis, en lo concerniente a las metas bélicas, entre la Alemania imperial y la nazi, peraltando, por tanto, en detrimento del mismo Auschwitz, el CAMINO a la barbarie desde 1914. Los apologetas del Sonderweg (los colegas de Koselleck en Bielefeld) pusieron énfasis en la vía infausta conducente a 1945 - luego estudiaron el protonazismo más bien que el nazismo-, aunque Wehler ha subsanado ese déficit en el último y discutido volumen de su serie Deutsche Gesellschaftsgeschichte (cfr. Lorenz, op. cit., pp. 362 ss.). 
hostil con otros enfoques alternativos — con la Sozialgeschichte tradicional (enraizada en la Strukturgeschichte y antes en la Volksgeschichte), la Begriffsgeschichte y la Alltagsgeschichte, vg.- - que se postulaban para conjurar la crisis que atenazaba a la historia por esos años. Los críticos por antonomasia habían hecho abdicación de la autocrítica, y, más allá de las vendettas de sus viejos adversarios - la anécdota del «trago» puede leerse en clave de venganza-, con ello se había difuminado tanto la delimitación entre esa panacea de la historia social crítica y una historia conservadora, en retirada tras el asedio al que la sometió Habermas, como, si nos remontamos a una polémica incluso anterior a la del revisionismo, la emancipación (que ahora se transfiguraba en una ladina apostasía) de la historia popular, nacional o étnica (Volksgeschichte). Justamente aquí entra en danza Conze. Su itinerario es similar al de Schieder - ambos, tras 1945, fueron considerados como renovadores, maestros y modelos, y ambos ocultaron los servicios prestados, no sólo a título individual sino también científico, al nazismo ${ }^{19}$.

Aunque el homenaje que le rinde Koselleck a Conze en 1987 (todavía a rebufo de la polémica de los historiadores), los denuedos por expurgarlo de todo asomo de racismo o antisemitismo y la explicación de su actitud frente al nazismo bajo el prisma de sublimación religiosa ${ }^{20}$ no dejan de resultarnos patéticos, a la luz de los nuevos datos que demuestran su connivencia con la ominosa política colonialista de deportaciones, desde sus inicios declaró abiertamente sus fuentes de inspiración: C. Schmitt, Heidegger y Gadamer, cuyas afinidades electivas con el régimen totalitario están lo suficientemente acreditadas o son objeto de justificada suspicacia. Pero si la honestidad del promotor de la Begriffsgeschichte está libre de toda sospecha, su artículo «La discontinuidad del recuerdo» (1998) ha causado perplejidad e incluso rechazo. Este trabajo aparece en un momento en que el ambiente está muy caldeado por la exposición fotográfica organizada por el Instituto de Investigación Social de Hamburgo (Hamburg Institut für Sozialforschung) con el título provocador: Guerra de exterminio. Los crimenes de la Wehrmacht en Europa Oriental 1941-1944 (Vernichtungskrieg. Die Verbrechen der Wehrmacht in Osteuropa 1941-1944). La exposición retomaba la veta explosiva sobre la que había llamado la atención Goldhagen y el debate subsiguiente acerca de

19 H.-U. Wehler, «Nationalsozialismus und Historiker», en Schulze/Oexle, op. cit., pp. 306-339, y Hans-Ulrich Wehler. Eine lebhafte Kampfsituation, pp. 50-61. J. Kocka argumenta que el cambio de la Volksgeschichte de la época nazi a la historia estructural y luego a la historia social de los años 50 fue (en el caso de Conze) mucho más que un cambio oportunista de etiqueta. Hasta 1945 se había ocupado casi exclusivamente de historia social agraria. En los años 50 trabajó la historia estructural de la Revolución industrial, la historia del proletariado y del movimiento obrero liberal y socialdemócrata. Las relaciones entre «Klassen» $\mathrm{y}$ «Schichten» fueron para él más importantes que las relaciones entre grupos étnicos («Zwischen Nationalsozialismus und Bundesrepublik», en Schulze/Oexle, op. cit., pp. 340-357).

20 «Werner Conze: Tradition und Innovation», en Historische Zeitschrift, vol. 245 (1987), pp. 529-543. 
quién, además de las SA y las SS, perpetró aquellos horrendos crímenes, y lo hacía hurgando en un tema tabú durante mucho tiempo: la participación de la Wehrmacht en el Holocausto. Era un tema particularmente delicado porque la tesis oficial hasta entonces consistía en disociar el liderazgo político y la nación alemana, transfiriendo la culpa y la responsabilidad de los «crímenes execrables» a la élite nazi y a sus más directos esbirros, y, por lo tanto, dejando al margen, o al menos en un cómodo purgatorio, al ejército, manipulado por la canalla de la cúpula nazi. Además, a los supervivientes de este ejército se les encomendó la misión de refundar las Alemanias de la posguerra y algunos asumieron como su principal proyecto de vida dicha legitimación. Hacer cada vez más porosa esa frontera, asimilando la limpia (saubere) Wehrmacht a los verdugos (cuando se les hacía pasar también por víctimas), comportaba mezclar potencialmente a todo el pueblo alemán en esa sucia guerra (veinte millones de ciudadanos sirvieron en el ejército, que incluía virtualmente a cualquiera, a todo el mundo) y extender sin matices la mancha de la responsabilidad. La mencionada exposición, excepción hecha de algunos errores que la flor y nata del gremio rentabilizó para solicitar su clausura ${ }^{21}$, probó la intervención de unidades de la Wehrmacht en las masacres de civiles. En suma, parecía no haber «otra» Alemania, inocente, y se cernía de nuevo una amenaza antes más ficticia que real, la de la culpa colectiva (Kollektivschuld). Por esos años se tendió un puente entre la memoria colectiva y la culpa colectiva ${ }^{22}$, enfatizando la existencia de ambas - más allá de en el terreno de la imaginación obsesiva y de la manía persecutoria.

Koselleck adopta el punto de vista de un veterano de guerra inmerso en la ignorancia, se sobreentiende que propia y ajena, de lo que estaba sucediendo, apuntándose al axioma de la saubere Wehrmacht, esto es, de la candidez de los soldados y abundando en otros clichés que no pueden sino despertar recelos: El Todesfurcht (miedo de muerte) de los combatientes alemanes al Ejército Rojo, la ausencia total de algún conocimiento por parte de éstos sobre los campos de concentración y el Holocausto, el gran número de víctimas civiles alemanas a causa de los bombardeos aliados, la expulsión y violación en

21 Así, p. ej., los directores o ex directores del Institut für Zeitgeschichte de Múnich, del Militärgeschichtliches Forschungsamt y del Verein der Historiker Deutschlands, Horst Möller, Rolf-Dieter Müller y Lothar Gall, respectivamente, pidieron su cierre definitivo. Sobre la implicación de la Wehrmacht en los crímenes nazis hay que mencionar los libros de Jochem Böhler (Auftakt zum Vernichtungskrieg, Frankfurt, Fischer, 2006) y de Johannes Hürter (Hitlers Heerführer. Die deutschen Oberbefehlshaber im Krieg gegen die Sowjetunion 1941/42, München, Oldenbourg, 2006, que es parte del proyecto de investigación «Wehrmacht en la dictadura nacionalsocialista» del Institut für Zeitgeschichte de Múnich, el cual, como es sabido, fue muy crítico con la exposición auspiciada por los colegas de Hamburgo) y la muestra itinerante «"Was damals Recht war...". Soldaten und Zivilisten vor Gerichten der Wehrmacht», inaugurada en Berlín en 2007.

${ }^{22}$ Aleida Assmann, «Ein deutsches Trauma? Die Kollektivschuldthese zwischen Erinnern und Vergessen», en Merkur, 53/12 (1999), pp. 1142-1155. 
masa, la imposibilidad de comprender el Holocausto e incluso la exoneración penal de los asesinos de las SS. Se ha sugerido una similitud entre la perspectiva de Andreas Hillgruber y la de Koselleck. En Zweierlei Untergang. Die Zerschlagung des Deutschen Reiches und das Ende des europäischen Judentums (1986) Hillgruber yuxtapone los destinos «catastróficos» de la población alemana (incluyendo la Wehrmacht) durante la guerra y de los judíos, sin establecer ninguna conexión directa entre ambos y elevando la pérdida de los territorios alemanes en Europa oriental a la consecuencia más grave de la conflagración, echando más leña al fuego de la Historikerstreit. Hillgruber deslinda al pueblo del régimen nazi, victimando a la Wehrmacht, junto a la nación que nutre sus filas. La categoría de víctima fue dilatada sutilmente hasta abarcar a los caídos mientras estaban al servicio en la Wehrmacht y las SS ${ }^{23}$.

\subsection{La mala memoria de Minerva: docta ignorancia o diversos modos de saber y no saber}

El artículo «Die Diskontinuität» integra, junto a otros dos ${ }^{24}$, un apartado que la revista Deutsche Zeitschrift für Philosophie dedicó monográficamente al

23 «El 10 de mayo de 1945 fui ingresado en Auschwitz como prisionero de guerra de los rusos, y, hasta ese momento, nunca había oído el nombre de Auschwitz, no sabía nada de la existencia de ese campo de concentración, y ésa era por cierto la experiencia generalizada de mis compañeros de cautiverio, unos 30.000 que fueron a parar al campo principal» («Die Diskontinuität der Erinnerung», en Deutsche Zeitschrift für Philosophie, 47 (1999) 2, p. 213). «No todo hombre de la SS era como individuo un criminal. [...]. Y todos sabemos que los verdaderos asesinos que regresaron no pueden designarse criminales en el sentido ordinario de la palabra, porque, después de su regreso, eran ciudadanos normales y no fueron reincidentes en el sentido del derecho penal. Éste es justamente el problema: que era el ciudadano normal el que había cometido los crímenes. Ésta es la tesis que Goldhagen trae a la memoria con parte de razón» (p. 217). Lorenz se excede cuando declara que Koselleck no muestra mucha empatía hacia las víctimas de los alemanes (Lorenz, op. cit., pp. 376-378, 359-360). Una tía materna esquizofrénica murió en uno de esos campos como resultado del programa de eutanasia, su propio padre fue represaliado y su hermano murió durante un bombardeo. En el plano ya teórico llevó a cabo un estudio de la mutación del concepto de «víctima» (Opfer), que le llevó a oponerse al plan del mismísimo Kohl de instalar una Pietà de la escultora Käthe Kollwitz en Die Neue Wache y de convertirla en un memorial nacional a las víctimas de la guerra y de la tiranía, y a defender la necesidad de que el monumento al Holocausto berlinés se dedicara a todas las víctimas del régimen nazi sin excepción: los física y mentalmente discapacitados, los gitanos, los prisioneros soviéticos de guerra, los homosexuales, los sometidos a trabajos forzados, los asociales...

24 Me refiero al explosivo artículo de G. Wolters, «Der "Führer" und seine Denker. Zur Philosophie des "Dritten Reichs") (a partir de ahora lo abreviaremos con GW), y al de H. F. Fulda, «Heinrich Rickerts Anpassung an den Nationalsozialismus» (pp. 223-251, 253-269). En lo tocante a la intervención de Koselleck, el organizador, Fulda, quiere dar la palabra al «modo genuinamente filosófico» en que el catedrático de Bielefeld se ocupa de semántica histórica y de cuestiones de Histórica referidas a la historia contemporánea (zeitgeschichtlicher Historik)» (p. 211). Luego el anfitrión de este encuentro reconoce, en primer lugar, la veta filosófica del «historiador pensante», y, en segundo lugar, el engarce del tema del «recuerdo» no sólo con la Semántica Histórica (historische Semantik), sino también con un nivel que está en un escalón teórico superior, la Histórica (Historik). 
tema «Nacionalsocialismo y Filosofía». El Departamento de Filosofía de la Universidad de Heidelberg invitó en 1998 a tres ponentes. Si el estamento de historiadores, aun de manera vergonzosamente diferida, estaba emprendiendo una operación de autotransparencia, ajena a Koselleck, el nicho académico de la Filosofía también debería enfrentarse a su infame pasado, más allá del caso ejemplar y notorio de Heidegger ${ }^{25}$. Los tres conferenciantes pertenecían a grupos de edad diferentes: al de los participantes en la guerra, a la primera generación «escéptica» de la posguerra y a los nacidos al final o después de la contienda.

Koselleck escribió en 2003 una larga necrológica de Gadamer para el Süddeutsche Zeitung, donde pide que le sea permitido como historiador defender a Gadamer de los cargos de oportunismo formulados contra él en Heidelberg cinco años atrás. Implícitamente alude a la ponencia de Wolters, «El Führer y sus pensadores. Sobre la Filosofía del Tercer Reich»: «Hace 5 años, precisamente aquí en Heidelberg, se formuló la chocante tesis de que entre 1933 y 1945 hubo sólo tres tipos de alemanes: los nazis malos, los resistentes (Widerstandskämpfer) buenos y en medio el gran grupo, el de los oportunistas. Gadamer es uno de sus representantes. Aquí prefiero atenerme a la máxima de un historiador: Saber es mejor que saber mejor (Wissen ist besser als Besserwissen). La anticipación de una tipología dicotómica de bueno y malo impide entender los conflictos insolubles en los que todos los que vivieron entonces se vieron involucrados. Sobre esa mayoría que estaba en medio hay que decir que todos ellos estuvieron implicados en el régimen nacionalsocialista, como escépticos o adaptados, como utópicos o ralentizadores. ¿Quién puede seleccionar aquí sólo según el bien y el mal? El juicio moral es, hoy como entonces, siempre necesario, pero lamentablemente no fue constitutivo para lo que sucedió».

Gadamer perteneció a una cohorte generacional (nacida en 1900) de la que muchos se consideraron demasiado tardíos, héroes malogrados de la Primera Guerra Mundial, que alimentaron después con creciente radicalismo el ala dura y brutal de las SS. Gadamer jamás los secundó, ni en 1918, cuando empezó a estudiar, sin presentarse voluntario en el frente, ni con posterioridad. Mientras que la mayoría de sus colegas ingresaron en el partido, Gadamer nunca lo hizo. Y se atrevió a salvar de la muerte con un informe a Werner Kraus, que estaba en manos de la Gestapo.

Pero tras la Segunda Guerra Mundial cambió algunas frases sobre la preeminencia de lo alemán que había expuesto en París en 1941, tras la victoria sobre Francia, ante oficiales prisioneros de esa nacionalidad: «Como autor tiene derecho a retirar de la circulación frases que post festum inducen a ma-

25 H. F. Fulda, «Schwerpunkt: Nationalsozialismus und Philosophie», pp. 204-205. El escozor que, no obstante, continúa produciendo este asunto queda ilustrado con la negativa del comité de redacción de los Heidelberger Jahrbücher — donde iban a aparecer inicialmente- a publicar los tres trabajos (sólo aceptó uno) (ibid., p. 208). 
lentendidos. Como historiador debo lamentarlo», dice Koselleck amparándose en la distinción leibniziana entre verdades de hecho y verdades de razón. Las vérités de fait pueden pensarse como contingentes, y con ello su opuesto es posible. Las vérités de raisonnement, en cambio, excluyen forzosamente su opuesto. Las verdades de hecho son tan reales como superables, las de razón son irrefutables. Es inútil querer negar datos históricos ocurridos alguna vez porque parecen oponerse a una convicción posterior ${ }^{26}$.

Es una cuestión aún controvertida la filiación política de Gadamer durante el nacionalsocialismo y ni su autobiografía ni la biografía de Grondin logran zanjarla. Pero, dado el tono desdeñoso del historiador, es justo recordar el contenido de la denostada conferencia de Wolters. A éste, al igual que ocurrió en el caso de los historiadores, le extraña la falta de conocimiento exacto sobre la filosofía y los filósofos en el Tercer Reich. Heidegger es la excepción que confirma la regla. Era uno, junto a Erich Rothacker, que luego sería maestro de Apel y Habermas, de los que querían «guiar al guía» (den Führer führen). El conferenciante recomienda «una clasificación de los pensadores en el Reich del "Führer" en tres grupos. Me gustaría denominarlos "nazis", "oportunistas" y "rectos" (Aufrechte). [...]. Se consideran filósofos nazis a todos aquellos que fueron miembros del partido nazi. Pero una ojeada a la lista de los "compañeros de partido" filosóficos del "Führer" muestra que no todos los allí inscritos pueden considerarse seriamente como pensadores del "Führer"» (GW, p. 231).

Más adelante prosigue: «Así, hasta donde sé, al menos las contribuciones a una filosofía nazi propia de compañeros de partido como Heinz Heimsoeth, Gottfried Martin, Joachim Ritter o Vinzenz Rüfner son insignificantes, si acaso existen. Por otro lado, hay al menos un filósofo, que considero nazi, pero

26 Gadamer habría podido invocar su lección inaugural en Leipzig en 1939 para defenderse del reproche formulado ex post. Allí todos los oyentes sabían a qué se refería cuando acuñó la premisa mayor: «Todos los burros son pardos». ¿Quién se hubiese atrevido a exhortarle a declarar abiertamente: «Todos los pardos son burros»? Esto sólo se lo pregunta quien hubiese sobrevivido a esta frase. Y en 1942 cualquier lector sabía leer cuando Gadamer negó la tesis de que el Estado platónico se basa en la alternativa de amistad y enemistad. Sólo la justicia común para cada uno funda una res publica. Y si Gadamer continúa escribiendo que los tiranos no tendrían amigos, esto lo entendieron todos, incluso aquellos que se sabían amigos de quien no podía ser llamado tirano. Pero el arte de leer entre líneas, un viejo arte hermenéutico, ha caído mientras tanto en el olvido. Quien clasifica - sin valoraciones - a Gadamer de oportunista, se parece a alguien que pide $a$ posteriori al soldado Schweijk que mejor no hubiese sido soldado (Süddeutsche Zeitung, 14 de marzo de 2003). En la ya citada publicación de 2004, Wolters vuelve a la carga, poniendo a Gadamer como ejemplo de eliminación de la «disonancia cognitiva» al haber purgado en las reediciones de ese texto parisino las alusiones al «völkisches $\mathrm{Pa}-$ radigma» (Vertuschung, Anklage, Rechtfertigung, pp. 35-40). Ha habido otras tentativas de formular criterios de un filósofo o ciencia nacionalsocialista (cfr. Hans Jörg Sandkühler, «"Eine lange Odyssee". Joachim Ritter, Ernst Cassirer und die Philosophie im "Dritten Reich"», en Dialektik, 2006/1, pp. 147-149, 155-158, 175-177 —aquí se estudia el caso de otro adaptado al régimen nazi, J. Ritter-). 
que no aparece en la lista de los miembros del partido: es el discípulo de Husserl Oskar Becker [...].

Por eso propongo otros criterios, de los cuales uno debe bastar para caracterizar a un filósofo como filósofo nazi: 1) Actividad política (no mera militancia) en organizaciones nazis relevantes o actividad conforme al partido en puestos del gobierno y de la administración; y 2) publicaciones u otras manifestaciones que pueden entenderse como contribuciones a la ideología nazi, en particular aquellas que defienden la primacía de la raza "aria" o un derecho de Alemania a la conquista de un "Lebensraum". En este sentido pueden llamarse, por citar sólo a algunos de los más prominentes, a Alfred Baeumler, Oskar Becker, Arnold Gehlen, Martin Heidegger, Ernst Krieck, Erich Rothacker y Helmut Schelski, al menos temporalmente, filósofos nazis.

Como "rectos" me gustaría designar a aquellos que de ningún modo estuvieron dispuestos a colaborar, ni institucional ni intelectualmente. También podría decir que los honestos son aquellos filósofos que lograron blindar sus discursos frente al discurso del Führer o discursos afines, reconocidos oficialmente. Este grupo naturalmente no es grande» (Ernst von Aster, Theodor Litt, Aloys Wenzl, Hans Pfeil, Viktor Kraft, Heinrich Scholz, Karl Jaspers, Carl Gustav Hempel (GW, p. 233) y el único filósofo alemán que pagó con su vida su resistencia: Kurt Huber, spiritus rector del movimiento de resistencia estudiantil muniqués «Rosa Blanca» de los hermanos Scholl). No cuenta, por motivos definitorios, a numerosos emigrantes judíos, porque ellos habrían tenido oportunidad de mostrarse «honestos» al precio de su vida.

Y continúa: «El grupo mayoritario lo forman sin duda los "oportunistas"». Con el término «oportunistas» designo a aquellos filósofos que no fueron nazis en el sentido preciso arriba indicado, pero que tampoco rechazaron el régimen completamente como lo hicieron los «honestos». Fueron todos aquellos que, a causa de determinadas ventajas, en particular de la seguridad y el desarrollo de una existencia profesional, llegaron a compromisos externos de diferente tipo en contra de sus verdaderas convicciones o cuyos discursos filosóficos convergieron de una manera no demasiado fuerte con la cosmovisión del Führer.

Como ejemplo paradigmático de compromisos externos puede servir aquí Hans-Georg Gadamer. En sus Años de aprendizaje filosófico reconoce: «Mi propósito era, evidentemente, el de salvar mi existencia académica en Alemania, pero por otro lado tampoco deseaba hacer ninguna concesión política que pudiera costarme la confianza de mis amigos emigrados tanto en el interior como en el extranjero. Por tanto, ni siquiera tomé en consideración la posibilidad de ingresar en el partido (Parteiorganisation). Por fin, seguí una vía que luego se demostraría acertada. En aquella época había unos cursos de instrucción para profesores no titulares principiantes, luego exigidos para el posible ascenso a cátedra (eine Art politischer Schulungskurse für angehende Privatdozenten, die für jede Habilitation verlangt wurden). Me ofrecí como volun- 
tario para uno de aquellos "campos" (Lager), conocidos como Academia de docentes, a fin de "rehabilitarme" (meine Rehabilitation), desplazándome con este motivo a Weichselmünde, cerca de Dantzig, algunas semanas en el otoño de 1936» ${ }^{27}$. Wolters puntualiza que Gadamer parece olvidar que ingresó el 1 de agosto de 1933 en la Federación nacionalsocialista de enseñantes (Nationalsozialistischen Lehrerbund) (NSLB) como miembro n. ${ }^{\circ}$ 254.387. Por «Parteiorganisation» entiende él más bien el NSDAP o las SA o SS. Los cálculos de Gadamer son conocidos: Ya en la primavera de 1937 podía anunciar el título de Professor, al que le siguió en 1938 la cátedra de Lepizig. Wolters dice expresamente que no plantea aquí si el discurso filosófico de Gadamer delata complicidad con el ideario nacionalsocialista, como ha sostenido Teresa Orozco (Platonische Gewalt. Gadamers politische Hermeneutik der NS-Zeit, Hamburgo, Argument, 1995).

Se trata aquí sólo de una tipología descriptiva con vistas a ordenar la diversidad. Obviamente tiene esta tipología - como ya sugieren las designaciones - también una dimensión moral. Sin embargo, para el juicio moral son necesarias consideraciones ulteriores que van más allá de lo descriptivo. El mismo acto, descriptivamente, de la participación oportunista en un Dozentenlager obtiene una cualidad moral diferente, dependiendo de, p. ej., si fue emprendida por un Privatgelehrter pudiente o, digámoslo así, por un padre de familia muerto de hambre ${ }^{28}$. Hasta el ingreso en el partido nazi no tiene por qué ser reprobable moralmente eo ipso. Lo reprobable de este acto debe ser posiblemente ponderado - en una perspectiva consecuencialista - respecto a algo moralmente importante que quizá así se consiguió. Por lo demás, hay que poner siempre en guardia, en lo concerniente al juicio moral, frente a la jactancia: «ninguno de nosotros sabe cuál habría sido su posición entonces. Si en nuestro contexto designo a un filósofo como "oportunista", esto no significa ningún veredicto moral. La experiencia histórica sugiere más bien que la gran mayoría de nosotros habríamos procedido de manera oportunista. Me pregunto y les pregunto si siquiera uno de nosotros se encontraría entre los "honestos", si hubiésemos estado expuestos a la misma presión y a las mismas tentaciones que nuestros colegas de hace 60 o 70 años» (GW, pp. 234-235) ${ }^{29}$.

27 Barcelona, Herder, 1996, p. 64; cf. Philosophische Lehrjahre, Frankfurt a.M., Klostermann, 1977, p. 56.

28 En una nota a pie de página apostilla: «en un caso extremo el oportunismo puede incluso ser ordenado moralmente. Sería el caso, por ejemplo, de si mediante un comportamiento oportunista (como el ingreso en el partido) fuesen salvadas vidas humanas. Pero entre los filósofos alemanes no veo a nadie que pueda reclamar para sí tal cosa o similar» («Der Führer und seine Denker», p. 235).

29 Wolters analiza la actitud de Gadamer frente a un «auténtico filósofo nazi», Oskar Becker, a quien éste último trató de rehabilitar. Lo cual contrasta con la imagen que de Becker nos ofrece Löwith en Mi vida en Alemania antes y después de 1933, libro prologado por Koselleck (ibid., pp. 240-241) En Philosophische Lehrjahre describe así a Becker, «antiguo discípulo de Husserl y Heidegger, por entonces aún inhabilitado para impartir clases en Bonn, extremo que 
Luego la posición de Wolters es mucho más matizada de lo que parece insinuar Koselleck. Además, acaban de descubrirse alguna cartas de aquellos años, en las que Löwith le recrimina a Gadamer su inclinación «a dejar las cosas en suspenso y a sustraerse a la alternativa entre resistencia y acomodación (Widerstand und Anpassung)» mediante la evasión (Ausweichen) a los valores eternos de la cultura alemana. Detrás de la máxima hermenéutica «Comprender es todo» («Verstehen ist alles») ve él un «Comprender todo significa perdonarlo todo» («Alles Verstehen heisst alles Verzeihen») ${ }^{30}$.

Pero volvamos a otra máxima: «Saber es mejor que saber mejor» («Wissen ist besser als Besserwissen»). Esta sentencia, tan gadameriana prima facie, la repite Koselleck en dos documentos, uno autobiográfico y otro biográfico. El primero es un testimonio sobrecogedor aparecido dos días antes del 8 de mayo de 1995 sobre sus vivencias el día de la liberación (que para Koselleck, como para muchos miembros de la Wehrmacht, fue de cautiverio en manos de los rusos). Allí insiste en una distinción clásica en él entre experiencias primarias y secundarias: «Hay experiencias que se desparraman por el cuerpo como masa de lava incandescente y se coagulan allí. Inconmoviblemente pueden volver a hacerse presentes desde entonces, en todo momento e inalterablemente. No muchas de esas experiencias pueden pasar a ser recuerdos, pero, si es así, entonces se basan en su presencia sensible. El olor, el sabor, el ruido, el sentimiento y el campo visual, en suma, todos los sentidos, con placer o dolor, vuelven a despertarse y no necesitan de ningún trabajo de la memoria para ser y permanecer verdaderos ${ }^{31}$.

no era tanto debido a que hubiera sido un nazi — ni a su calidad de miembro de número del partido - , sino al conocimiento que se tenía de su teoría de las razas — en las que, sin embargo, no se hallará traza alguna de antisemitismo-y de su cultivo del más aguzado librepensamiento. [...]. Pero su apartamiento de la actividad docente no era en modo alguno merecido, y su posterior recuperación para la Universidad de Bonn, a la que pude cooperar situándolo en el primer lugar de la lista de nombramientos de profesores para la Universidad de Heidelberg, constituyó más tarde un acontecimiento de relevancia en la formación de una nueva generación filosófica, como de ello me darían luego fe otros profesores en activo en Bonn por aquellas fechas, tales como Apel, Habermas, Ilting, Pöggeler o Schmitz» (p. 174; ed. cast., p. 205). Una visión opuesta del «Dr. B.» la brinda su amigo de juventud Löwith (Mi vida en Alemania antes y después de 1933. Un testimonio, Madrid, Visor, 1992, pp. 67-78).

30 «Gadamers vergessene Koffer», en Information Philosophie, 4 (2005), p. 137.

31 Así se sentía cuando un vigilante polaco, que había estado prisionero en un campo de concentración, les instó a pelar patatas más deprisa, y amenazando a Koselleck con golpearle la cabeza con un taburete, finalmente se detuvo, arrojó el taburete a un rincón y exclamó: «“¿Para qué voy a romperte la crisma? Vosotros habéis gaseado a millones”. De repente - literalmente - tuve claro que decía la verdad. ¿Gaseado? ¿Millones? Eso no podía ser inventado». Hay experiencias de la guerra (p. ej., cuando supo que una tía suya, en el marco del programa de eutanasia, no sólo había sido asesinada, sino también gaseada) que tienen que hacerse siempre de nuevo una y otra vez, porque las experiencias primarias no bastan para garantizar toda la verdad. Siempre sobrevienen nuevas verdades: «En ese sentido, para mi generación, la guerra nunca se acaba o empieza siempre, una y otra vez, en la medida en que viejas experiencias han de elaborarse de nuevo». 
[...]. Ciertamente, hay innumerables recuerdos que he contado y repetido a menudo, pero la presencia sensible de su verdad se ha desvanecido desde hace mucho tiempo. Son para mí sólo historias literarias, sólo puedo darles crédito escuchándomelas a mí mismo. Pero ya no puedo garantizar la certeza sensible. [...]. Hoy puedo calibrar, por supuesto sólo secundariamente y ex post, lo que significó Auschwitz para aquellos abocados a la muerte y para aquellos supervivientes...Tal como he dicho, durante algunos segundos había oído hablar del asunto, pero jamás tuve conocimiento de ello. [...]. Hay experiencias que no son intercambiables ni comunicables... Siempre pueden compararse, pero sólo desde fuera. Desde la experiencia respectiva de cada uno todo es único. Hoy sé mucho más de lo que podía saber entonces y sé cosas diferentes de las que entonces era posible saber. Y eso mismo les ocurre a los nacidos después. Pero la no intercambiabilidad del saber que proporciona una experiencia primaria no se puede superar. Saber es mejor que no saber» ${ }^{32}$.

En su necrológica, frente a la tentativa de catalogar a Gadamer como el representante por excelencia del oportunista durante el régimen nazi, Koselleck responde que prefiere atenerse a la máxima de un historiador: «Saber es mejor que saber mejor», para a continuación censurar la moralización de la historia ${ }^{33}$. Lo anterior está emparentado con un pasaje de Verdad y Método, correspondiente al epígrafe sobre la distancia temporal. Allí evoca a un autor apreciado por Koselleck, Chladenius, quien piensa que un autor no necesita conocer el verdadero sentido de su texto, y por eso el intérprete puede y debe comprender mejor que él. No sólo ocasionalmente, sino siempre el sentido de un texto excede a su autor. Por eso comprender no es sólo una actitud reproductiva, sino siempre y también productiva. Quizá no sea correcto hablar de «comprender mejor» para ese momento productivo que está en el comprender: «Comprender no es comprender mejor (Besserverstehen), ni en el sentido objetivo de saber más (im Sinne des sachlichen Besserwissens) en virtud de conceptos más claros, ni en el de la superioridad básica que posee lo consciente respecto a lo inconsciente de la producción. Bastaría decir que, cuando se comprende, se comprende de un modo diferente (anders)». No obstante, el saber que proporciona la conciencia de la historia efectual es diferente y mejor que el precedente, pero nunca es el mejor, esto es, un saber absoluto. Koselleck acepta esta tesis en la medida en que admite la posibilidad de la reescritura de la historia. El saber es un no saber que acicatea saber más y, por

32 «Glühende Lava, zur Erinnerung geronnen. Vielerlei Abschied vom Krieg: Erfahrungen, die nicht austauschbar sind», en Frankfurter Allgemeine Zeitung, 6.05.1995.

33 «Er konnte sich verschenken», en Süddeutsche Zeitung, 14.05.2003, p. 14. Ya en su tesis doctoral apela a la moralización de la política como explicación del terror («Eine totalitäre Antwort auf totalitären Terror», en Süddeutsche Zeitung, 16.02.2002). Gadamer embiste asimismo contra tal moralización [Verdad y Método (VM), Salamanca, Sígueme, 1977, pp. 349, 664-665]. 
tanto, mejor, sin alcanzar nunca la epifanía del non plus ultra exegético del sentido ${ }^{34}$.

En este contexto podemos comparar los menospreciados Besserverstehen y Besserwissen. Lo último sería propio de los que Koselleck despacha despectivamente como «administradores de las pretensiones colectivas de la memoria» - ¿lo es el profesor Wolters?_- pero también de los revisionistas - ¿no lo son entonces Hillgruber y Nolte? - Para Gadamer entender no equivale a entender mejor, porque la distancia histórica entre el texto y el intérprete impide la transposición psíquica (en el espíritu del creador) y la histórica (en el espíritu de la época). El romanticismo y el historicismo habían recurrido a este modelo reconstruccionista que gira en torno a la empatía y la congenialidad; pero la hermenéutica filosófica lo había cuestionado por la insalvabilidad de la distancia temporal. Mas para Koselleck, como para Gadamer, existe «verdad histórica» ${ }^{35}$. Incluso cabe sondear otro argumento gadameriano para impugnar la validez de ese dictum del historiador, que sin duda es un dicterio contra los sabihondos, los sabelotodos. Cuando Gadamer distingue la malversación ilustrada del concepto de autoridad, denigrada a burdo autoritarismo, de la «esencia de la autoridad», cifra el criterio de ésta en un acto de reconocimiento: «se reconoce que el otro está por encima de uno en juicio y perspectiva y que en consecuencia su juicio es preferente o tiene pri-

34 VM, pp. 366-367; Gesammelte Werke (GW), I, Tübingen, J. C. B. Mohr (Paul Siebeck), 1986, pp. 301-302. En Koselleck hallamos este pasaje: «En vistas al procedimiento mismo del manejo de las fuentes, se ofrecen ahora tres posibilidades que podrían dar lugar a una reescritura: En primer lugar, podrían aparecer nuevos testimonios. [...]. En segundo lugar, puede ser que nuevas cuestiones contribuyan a buscar y encontrar nuevos testimonios. [...]. En tercer lugar, los testimonios de que se dispone pueden ser leídos e interpretados nuevamente. [...]. En la praxis actual estos tres procedimientos de utilización del testimonio escrito son empleados y combinados al mismo tiempo. Pero desde el punto de vista diacrónico cabe suponer que se trata de un progreso cognoscitivo acumulativo. [...]. En este sentido sabemos más acerca de nuestro pasado y, metodológicamente, lo sabemos mejor (besser Bescheid) de lo que podían conocerlo las generaciones anteriores» (Estratos del tiempo, pp. 76-77). La actitud de Koselleck respecto a Gadamer y de los discípulos de Joachim Ritter de la primera y de la segunda generación respecto a su maestro (estos es, su silencio sobre la biografía del catedrático de Münster entre 1933 y 1945, en que participó en actividades de organizaciones nazis) contrasta con la de otro doctorando del último, H. J. Sandkühler (art. cit., p. 161). Frente a la hermenéutica cohibida y a la defensiva de uno de los favoritos de Ritter, Hermann Lübbe, que achaca la acusación de trato insensible con el pasado nazi en los tardíos años 40 y 50 a la pérdida del sentido de la realidad histórica y, en el caso particular de Ritter, a la intención política de los años posteriores de deslegitimar moralmente la historia de la fundación de la segunda democracia alemana, destaca la gallardía de Sandkühler, para quien «no hay comprensión sin una hermenéutica activa de lo que fue y de lo que es». Los hallazgos sobre la vida de su maestro lo han decepcionado. Su decepción no estriba en que Ritter fue hasta 1945 como fue, sino en el final de un autoengaño: la imagen que admitió de él el estilo de pensamiento común de Münster se fundaba en un perfil amañado, sustentado sólo en partes: hasta 1933 y después de 1945 (art. cit., pp. 178-179).

35 «Ist Geschichte eine Fiktion? Interview mit Reinhart Koselleck», en Neue Züricher Zeitung-Folio, März, 1995, pp. 60-63. 
macía respecto al propio. La autoridad no se otorga, sino que se adquiere [...]. $\mathrm{Su}$ verdadero fundamento es también aquí un acto de la libertad y la razón, que concede autoridad al superior básicamente porque tiene una visión más amplia o está más consagrado (eingeweiht), esto es, porque sabe más (besser weiss)» $(V M, 347-348 ; G W$ I,284). Luego, invirtiendo la fórmula de Koselleck, «saber mejor es mejor que saber» y mucho mejor que el no saber de los siempre perversos rumores. Saber mejor es saber más aun sin saberlo todo; en dicción gadameriana, es un saber finito y no el saber absoluto. Recordar mejor no es recordarlo todo. Borges caricaturizó o tal vez dramatizó la tensión entre el ideal de una memoria absoluta y la imposibilidad e insensatez $-\mathrm{y}$ por consiguiente la esterilidad - de realizar esta antigua obsesión, tan profundamente humana. Funes el memorioso «no sólo recordaba cada hoja de cada árbol de cada monte, sino cada una de las veces que la había percibido o imaginado». El «inútil catálogo mental de todas las imágenes del recuerdo» lo hacía «casi incapaz de ideas generales, platónicas. No sólo le costaba comprender que el símbolo genérico perro abarcara tantos individuos dispares de diversos tamaños y diversa forma; le molestaba que el perro de las tres y catorce (visto de perfil) tuviera el mismo nombre que el perro de las tres y cuarto (visto de frente). [...]. Funes discernía continuamente los tranquilos avances de la corrupción, de las caries, de la fatiga. [...]. Era el solitario y lúcido espectador de un mundo multiforme, instantáneo y casi intolerablemente preciso. [...]. Sospecho, sin embargo, que no era muy capaz de pensar. Pensar es olvidar diferencias, es generalizar, abstraer. En el abarrotado mundo de Funes no había sino detalles, casi inmediatos». Entre los casos de memoria prodigiosa registrados en la Naturalis Historia de Plinio que Funes enumera es mencionado «Ciro, rey de los persas, que sabía llamar por su nombre a todos los soldados de sus ejércitos» ${ }^{36}$. Esta portentosa facultad mnemotécnica, como ha constatado Koselleck, se torna necesaria, cuando, a partir de la edad moderna, cada uno de los caídos conquista el derecho a ser conmemorado. Koselleck atisba un punto de inflexión con la irrupción de la modernidad en la estética de la memoria de los caídos. Por un lado, la entrada en esta nueva era hace coincidir la desaparición del sentido trascendente de la muerte con la pujanza de la pretensión intramundana de sus representaciones. El declive de la interpretación cristiana deja el camino expedito a interpretaciones sociopolíticas. Por otro, a tal funcionalización se añade la democratización: si la representación prerrevolucionaria de la muerte era distinta según los órdenes sociales del más acá, asistimos ahora a un despojo de las diferenciaciones estamentales tradicionales y a su sustitución por una vindicación igualitaria. Pero ya hemos transitado de la memoria a los memoriales.

36 «Funes el memorioso», en J. L. Borges, Narraciones, Madrid, Cátedra, 2002, pp. 122-123, 121. Cf. Lisa Regazzoni, «Introduzione» a Per un'estetica della memoria, en Discipline Filosofiche, XIII/2 (2003), pp. 5-6. Este monográfico contiene el artículo de Koselleck: «I monumenti: materia per una memoria collettiva». 


\section{La querella de los memoriales}

En el único debate en que Koselleck se ha implicado en cuerpo y alma, a veces como un David contra Goliat (esto es, contra Helmut Kohl en su pleno apogeo), con una comparecencia constante en medios de comunicación de todo signo, ha sido en el debate sobre el monumento a las víctimas del Holocausto. Este compromiso público no fue casual, sino el resultado de las investigaciones que desde hacía tiempo, exactamente desde los revueltos años 68-69, estaba llevando a cabo acerca de la iconología política, y más concretamente, de la iconografía de la muerte violenta. Él mismo parece elevar este debate al rango de una «nueva polémica de los historiadores» ${ }^{37}$. En varios trabajos había rastreado las metamorfosis de la estatuaria dedicada a los muertos en las guerras, destacando una serie de jalones. Desde la modernidad cabe identificar tres hitos: la Sattelzeit, la Primera y la Segunda Guerra Mundial. Reiteradamente ha negado la existencia de una memoria colectiva, como si hubiese un sujeto colectivo capaz de recordar. Todo recuerdo se forja primariamente a partir de las experiencias propias y los recuerdos que se derivan de ellas son individuales. Sólo las condiciones en las que se realizan y se recogen las experiencias pueden llamarse colectivas o supraindividuales.

Por eso conviene evitar la confusión entre, por un lado, las experiencias primarias (Primärerfahrungen) de aquellos que las han vivido en primera persona y a ellas ligan sus propios recuerdos y, por otro, las experiencias secundarias (sekundären) de aquellos que no han estado presentes en la ocasión que ha suscitado las experiencias inmediatas. Sondear racionalmente esta diferencia y verificarla es una vieja tarea de las ciencias históricas. Koselleck quiere que lo vivido no sea deslegitimado por lo aprendido con posterioridad, que la memoria retentiva no sea suplantada por la reconstructiva. Experiencia vivida y saber histórico no pueden concordar. La contradicción entre lo emocional y lo cognitivo apenas puede disolverse ${ }^{38}$.

El lenguaje no es el único medium en el que la historia se acrisola en el recuerdo o es experimentada como realidad. Los monumentos se refieren a un campo extralingüístico que llama ámbito de la sensibilidad política. Todos los mensajes de los monumentos son susceptibles de una doble lectura: recuerdan las incomparables ocasiones que han conducido a la muerte. Como las experiencias primarias, éstas no son intercambiables. Pero, al mismo tiempo,

37 «Der Historiker Reinhart Koselleck kritisiert die Gestaltung der "Neuen Wache” als nationale Gedenkstätte der Deutschen», en Tageszeitung, 13.11.1993. Remito a mi trabajo «Semántica histórica e iconografía de la muerte en Reinhart Koselleck», que aparecerá en un volumen coordinado por J. Fernández Sebastián y Joao Feres.

38 «Im Gedächniswohnzimmer. Warum sind Bücher über die eigene Familiengeschichte so erfolgreich? Ein Zeit-Gespräch mit dem Sozialpsychologen Harald Welzer über das private Erinnern», en Zeitliteratur, März 2004, pp. 43-46; A. Assmann, «Erinnerung und Authentizität», en Universitas, 56/11 (2001), pp. 1127-1140. 
las respuestas artísticas a las ocasiones incomparables se repiten. La ilustración del recuerdo se nutre de una limitada gama de motivos, de un exiguo repertorio de soluciones artísticas, que obligan por eso a la repetición para visualizar la singularidad de la muerte en cada caso. La oferta iconológica de los monumentos en su conjunto se transforma sólo lentamente y a largo plazo, y se vuelve lacerante la discrepancia entre la acelerada experiencia de la muerte - y por eso olvidable - y la creciente dificultad para fijar permanentemente su recuerdo ${ }^{39}$.

Un fenómeno nada baladí en la extensión iconográfica de la Begriffsgeschichte está enlazado con un cierto humus epocal, del que participan casi todos los padres fundadores de la historia conceptual. La preocupación por los monumentos forma parte de la cultura estética de la preservación, que constituye un contrapeso - el término «técnico» empleado es «compensación»—a la civilización moderna ultraveloz. Si Koselleck convierte la aceleración de la experiencia en signo de la modernidad, ella es sobre todo una experiencia de amnesias aceleradas, de una aceleración sin igual del olvido. Esa noción de «compensación» ha sido elaborada por los miembros del denominado Collegium Philosophicum de Münster, Joachim Ritter, Odo Marquard y Hermann Lübbe ${ }^{40}$. Con la conservación de monumentos, «mantenemos a los pasados como pasados propios, aprehendibles e imputables». Esa conservación es una compensación a la erosión de experiencia causada por la gran velocidad de modificación de las condiciones civilizadoras de la vida, con el consiguiente envejecimiento ultrarrápido de las tradiciones — entendidas como orientaciones de validez transgeneracional.

En el «Prólogo» a Estratos del tiempo anunciaba la futura publicación de otros dos volúmenes, el dedicado a la «teoría y praxis de la historia conceptual», que acaba de salir de la imprenta en 2006, y los «estudios historiográficos sobre la historia de la percepción» ${ }^{41}$. La semiótica terminológica se completa con una semiótica visual. El interés por la iconografía de la muerte violenta está arraigado en su metahistoria, en su antropología de la experiencia histórica, en la que el par Sein-zum-Tode y Sein-zum-Totschlagen teje la trama de las condiciones de posibilidad de las historias. La antítesis mo-

39 «Vorbemerkung zur gegenwärtigen Debatte über den politischen Memorialkult», epígrafe preliminar correspondiente a su trabajo «Die bildliche Transformation der Gedächtnisstätten in der Neuzeit», en Jean-Charles Margotton y Marie-Hélène Pérennec, $L a$ mémoire, Presses Universitaires de Lyon, 2003, pp. 7-9.

40 «Pérdidas de experiencia y compensaciones. Acerca del problema filosófico de la experiencia en el mundo actual», en Filosofía práctica y Teoría de la Historia, Barcelona, Alfa, 1983, pp. 158, 168-169; O. Marquard, «Zukunft und Herkunft. Bemerkugen zu Joachim Ritters Philosophie der Entzweiung», en Kurt Röttgers (ed.), Politik und Kultur nach der Aufklärung. Festschrift Hermann Lübbe zum 65. Geburtstag, Basel, Schwabe, 1992, pp. 101 ss.

41 Zeitschichten, Frankfurt, Suhrkamp, 2000, p. 7. El primer libro anunciado lleva el título de Begriffsgeschichten, Frankfurt, Suhrkamp, 2006. 
rir/matar es una categoría trascendental de la Histórica ${ }^{42}$. El hombre suele ser definido como un ser pensante y parlante, pero igualmente puede definirse como el ser capaz de matar a su semejante. Las unidades de acción política se constituyen mediante exclusión, sumisión y muerte de otros. Esta fundación de sentido se ha mantenido a lo largo de los siglos: «Ciertamente, mi semántica y mi iconografía e iconología están configuradas paralelamente. Lo que no es decible (sagbar) acaso es mostrable (zeigbar), y lo que no se puede mostrar (zeigbar) quizá se puede decir. Mostrar es siempre al mismo tiempo silenciar (verschweigen). Esto se corresponde también con los criterios de selección de conceptos fundamentales. La cuestión de umbrales comparables en la evolución del culto monumental y del lenguaje político puede enlazarse con ello. [...]. La democratización del culto a los muertos es un proceso que se inició con la Revolución Francesa y en cierto modo periclitó tras la Segunda Guerra Mundial. Hasta la Segunda Guerra Mundial todos los símbolos funerarios, monumentos y lugares de memoria estaban orientados hacia la fundación de sentido (sinnstiftend). [...]. Desde la Segunda Guerra Mundial... quien pregunta por el sentido de la muerte de soldados más bien provoca... Todo el paisaje iconográfico tematiza ahora la imposibilidad de fundar un sentido [...] la absurdidad misma» ${ }^{43}$.

La Revolución Francesa marca una divisoria - como la marcaba en la transformación de la experiencia histórica - en esta particular iconología tánica, y recurre a hipótesis ya compulsadas en el escrutinio del origen de la modernidad expuestas en Geschichtliche Grundbegriffe: temporalización, politización, ideologización y democratización. También los soldados desconocidos deben ser recordados, como consecuencia de la decisión democrática de no olvidar a nadie que ha dado su vida por todos. Constata una perseverancia iconográfica desde la Revolución Francesa hasta la Segunda Guerra Mundial, que comienza a resquebrajarse con las catástrofes de la Primera, que parecen irrepresentables mediante monumentos.

Algunos suspicaces han visto en el debate sobre el Holocaust-Mahnmal de Berlín una «segunda represión del pasado nazi disfrazada de una discusión permanente». Según ellos, la representación sustrae toda la atención a aquello que supuestamente debería ser representado, esto es, la autocompla-

42 Historia y Hermenéutica [1987], Barcelona, Paidós, 1997, pp. 73-77; «Kriegerdenkmale als Identitätsstiftungen der Überlebenden», en O. Marquard y K. Stierle (eds.), Identität, München, Fink, 1979, p. 257; Der politische Totenkult: Kriegerdenkmäler in der Moderne, München, Fink, 1994, pp. 9-10; Zur politischen Ikonologie des gewaltsamen Todes. Ein deutsch-französicher Vergleich, Basel, Schwabe, 1998, p. 5.

43 «Zeit, Zeitlichkeit und Geschichte - Sperrige Reflexionen. Reinhart Koselleck im Gespräch mit Wolf-Dieter Narr und Kari Palonen», en J. Kurunmäki y K. Palonen (eds.), Zeit, Geschichte und Politik. Zum achtzigsten Geburtstag von Reinhart Koselleck, University of Jyväskyla, 2003, pp. 22-23 — cito según una versión mecanografiada facilitada por Annita Kananen-; «Die Utopie des Überlebens. Der politische Totenkult der Neuzeit», en Neue Zürcher Zeitung, 12.03.1994, p. 65. 
cencia en la controversia impulsa un desvío hacia referencias heterónomas, favoreciendo una neutralización teórica, trascendental (también estética), en detrimento de la investigación empírica del Holocausto. En el estridente circo del recuerdo hasta el exceso se ocupan los mass media del Tercer Imperio, pero con ello ya no se trata de la verdad, sino sólo de los alemanes mismos. El libro de Götz Aly sobre Hitlers Volksstaat. Raub, Rassenkrieg und nationaler Sozialismus (2005) ha hecho estallar definitivamente la mentira del pueblo ignorante y de su sacrificio a causa de la locura nazi. A la inversa, el pueblo fue el primer beneficiario, sobre todo, la gente sencilla. No tenían que odiar a los judíos para alborozarse con la idea de heredar los abrigos de pieles, las viviendas y las joyas de los deportados. Nadie puede afirmar no haber sabido nada del genocidio ni de los saqueos de los territorios ocupados, pues todos se aprovecharon de ello. De hecho no es el honesto interés en la realidad nazi lo que aumenta, sino algo diferente: la ocupación narcisista consigo mismos ${ }^{44}$.

En un artículo sobre el proyecto del monumento berlinés al Holocausto, Habermas ubica la discusión en el contexto de la «autocomprensión política» de los alemanes, de la asunción de la responsabilidad política de los actos nefandos de la generación de los ejecutores («Tätergeneration»), esto es, de la memoria autocrítica de Auschwitz como pieza básica de la identidad nacional rota - «rota», porque aquí una quiebra, «nunca más», en la continuidad se troca en la condición de la autoestima- Si el monumento ha de ser la respuesta a esa cuestión no puede tener como sentido genuino el recuerdo de las víctimas judías en el país de los criminales ${ }^{45}$. El sentido del monumento tampoco puede residir en convertir el Holocausto en mito fundacional de la Re-

${ }^{44}$ Lorenz, op. cit., p. 367; véase el artículo de Jens Jessen en Die Zeit, 23.03.2005, p. 45. El libro de Aly, traducido como La utopía nazi. Cómo Hitler compró a los alemanes (Barcelona, Crítica, 2006), contiene unos corolarios contundentes: «El sistema funcionaba en provecho de todos los alemanes. En definitiva, todos y cada uno de los Volksgenossen - no sólo algunos funcionarios nacionalsocialistas, sino el 95 por 100 de los alemanes - se beneficiaba de lo robado, ya fuera como dinero recibido del Estado o como comestibles importados de los países ocupados y pagados con el dinero y el oro robado. Las víctimas de los bombardeos se vestían con la ropa de los asesinados y dormían en sus camas, aliviados por haberse salvado una vez más y agradecidos al Estado y al partido que les habían ayudado tan rápidamente. No se podrá entender el Holocausto mientras no se analice como el más consecuente atraco homicida de la historia moderna» (p. 322). «La unidad entre pueblo y dirección extrajo su funesta estabilidad, no de una propaganda ideológica refinada, sino sobre todo del saqueo y del reparto del botín, sociopolíticamente "equilibrado", entre los Volksgenossen alemanes» (p. 328). «El concepto que he propuesto de "dictadura consensuada con un respaldo mayoritario", debe ahora entenderse de forma más concreta: ese consenso mayoritario no emanaba de un convencimiento ideológico, sino del soborno sistemático mediante el bienestar social» (p. 338).

45 «Der Zeigefinger: Die Deutschen und ihr Denkmal. Zehn Jahre nach dem Mauerfall: Die Mahnmal-Debatte ist ein Streit um das politische Selbstverständnis der Deutschen. Die Berliner Republik wirft ihre falschen Schatten voraus, des Kanzlers telegene Auftritte entsorgen die Vergangenheit. Zum Stand einer Debatte», en Die Zeit, 31.03.1999, pp. $42-44$ [versión castellana en Pasajes, 1 (1999), pp. 27-35]. 
pública Federal, sino que su objetivo se cifra en «exhortar (aufzufordern) a las generaciones venideras a tomar postura» respecto al significado de Auschwitz para la identidad de los alemanes. De ahí que el monumento (Denkmal) sea un «monumento admonitorio» (Mahnmal).

¿Por qué la exigencia que plantea el monumento es pretenciosa, excesiva -Zumutung mienta no sólo una exigencia (Forderung), sino que ella contiene algo difícilmente exigible - ? Una ristra de autores conocidos (Hermann Lübbe, Rudolf Augstein, Martin Walser) sostiene que lo es por la imposibilidad de erigir un monumento a la vergüenza propia, por su inconciliabilidad con la «tradición de un culto a las víctimas orientada hacia la muerte heroica», hacia «el sacrificio presuntamente voluntario por los objetivos supuestamente elevados de la propia colectividad». Es decir, estamos hablando de una veta explotada por el nacionalismo, que puso los «monumentos a los caídos» al servicio del «recuerdo triunfal de las víctimas activas que habían luchado por una nación que se afirmaba a sí misma». Esta «demanda desmedida» ( $Z u$ mutung) posee siquiera una doble virtualidad: por un lado, muestra la incompatibilidad del Holocausto (y de la responsabilidad que le corresponde a una sociedad civil democrática) con las formas convencionales del culto nacional a los muertos; por otro, metaboliza la mutación en el diseño de identidades colectivas: el universalismo propio de los Estados constitucionales democráticos es permeable al particularismo de la conciencia nacional. Y llegamos de esta manera al punto de fricción (aunque no parezca tal) con Koselleck y Christian Meier - proveedores de buena parte del arsenal de argumentos que acabamos de esgrimir- En suma, a la pregunta «Para quién» le subyace una tensión entre el universalismo moral (moralische) igualitario y el particularismo ético (ethischen) histórico, una escisión entre la conciencia centrada en los autores y la conciencia volcada en las víctimas, cuyo reflejo en la controversia discrimina entre los partidarios de dedicar el monumento a los judíos asesinados y los que abogan por dedicarlo a todas las víctimas sin excepción. Koselleck se hace eco del clamor universalista que se opone a cualquier «jerarquización de los grupos de las víctimas», pues, amén de implicar un sectarismo insidioso para los excluidos, cohonestaría la clasificación, ahora en el terreno de la memoria, de los criterios de selección de los verdugos. Luego en el camino del monumento se entrecruzan la intuición moral universalista — enarbolada, según Habermas, por Koselleck y Meier - y la intuición ética de un colectivo, y el francfortiano le reprocha sutilmente al historiador su falta de sensibilidad histórica, en la medida en que, si prescindimos de la «singular relevancia» (besonderen Relevanz) de los judíos para la vida social y cultural de los alemanes, se incurriría en el peligro de coadyuvar a la construcción de nuevo de «una falsa abstracción». Estamos aludiendo a la aporía que entraña, por un lado, la injustificabilidad moral del tratamiento diferencial de las víctimas (señalado con tino por Koselleck), y, por otro, el antisemitismo cultural, derivado del protagonismo social de los judíos a la sazón, sin 
el cual no habría habido ni motivación ni apoyo para esos actos infames. Koselleck parece neutralizar - algo inadmisible para Habermas - lo último con el «irreprochable mandato moral de tratar a todos por igual a la hora de recordar a las víctimas». Aquí late la imagen de Koselleck como un ilustrado sobrevenido, hipócritamente sobrevenido, en la medida en que había prodigado sus críticas a la hipocresía de la Ilustración. Pero la Ilustración es también hoy una actitud autorreflexiva, una metacrítica, una crítica de la Ilustración y de sus epígonos.

La semántica histórica alberga todos los ingredientes requeridos para animar un uso público de la razón histórica. La historia conceptual se troca en medio de autoesclarecimiento histórico del presente. Aquí nos hemos limitado a las dos únicas contiendas en las que se ha enfrascado directamente Koselleck, inescindibles de la cascada de polémicas que se han sucedido en Alemania. Una tiene que ver con la memoria, la otra con los memoriales, y en cada una prevalece un uso distinto de la razón histórica, privado en un caso, público en otro. Un capital inmarcesible amasado a lo largo de su trayectoria ha consistido en que ha atravesado casi todas las posiciones filosóficas e historiográficas de sus coetáneos: el giro social, el lingüístico, el contextual, el icónico..., sólo que él lo ha hecho con frecuencia antes, sin alharacas y sin premura. Un titán de la historia social crítica, J. Kocka, ha dado pruebas de magnificencia al glosar su figura en un texto titulado «El futuro del pasado. Un ilustrado comprometido»: «Largo tiempo considerado un intruso en el gremio, Koselleck ha terminado por convertirse en uno de sus clásicos. [...]. Sobre él se escribirán muchos libros» ${ }^{46}$.

46 «Die Zukunft der Vergangenheit. Ein engagierter Aufklärer: Jürgen Kocka zum Tod seines Lehrers, des grossen Bielefelder Historikers Reinhart Koselleck», en Der Tagesspiegel, 06.02.2006. En efecto, él ha sido uno de los escogidos para la reciente edición de Lutz Raphael, Klassiker der Geschichtswissenschaft, vol. 2, München, Beck, 2006, pp. 166-194. Curiosamente, en los discursos laudatorios que le dedicaron Johannes Willms, con motivo de la concesión del Premio de los Historiadores de la Ciudad de Münster en 2003 (Historikerpreis der Stadt Münster 2003, p. 10), e Ivan Nagel, con ocasión del quincuagésimo aniversario de su doctorado en Heidelberg [S. Weinfurter (ed.), op. cit., p. 27], ambos presentaban como «ilustrado» a quien siempre fue calificado de enemigo de la Ilustración. 